\title{
Single-Incision Multi-Port Appendectomy for a Patient with Situs Inversus Totalis First case report
}

Rajkumar J. S., *Akbar Syed, Anirudh J. R., Kishor C. M., Deepa Ganesh

$$
\begin{aligned}
& \text { استئصال الزائدة متعددة الأبواب بشق واحد في مريض مصاب } \\
& \text { بحالة أعضاء مقلوبة الوضع } \\
& \text { أول تقرير حالة }
\end{aligned}
$$$$
\text { جي سي راجكومار، سيد أكبر، جي. أنبريد، سي كيشور، قانش ديبا }
$$

\begin{abstract}
Situs inversus totalis (SIT) is a rare autosomal recessive condition involving the complete lateral transposition of the organs. When individuals with this condition suffer from appendicitis, associated pain and symptoms are usually present on the left side, resulting in diagnostic difficulties. Moreover, the laparoscopic removal of the left-sided appendix may pose practical problems during surgery. Removal of an inflamed appendix is generally performed using a multiple-port laparoscopy. We report a 22-year-old male who presented to the Lifeline Institute of Minimal Access Surgery in Chennai, India, in April 2015 with pain in the left iliac fossa. Chest X-rays and ultrasonography confirmed SIT with an acutely inflamed appendix on the left side. The patient underwent a single-incision multi-port laparoscopic appendectomy with a successful outcome. To the best of the authors' knowledge, this is the first report in the literature of a single-incision multi-port appendectomy in a patient with SIT.
\end{abstract}

Keywords: Laparoscopy; Appendectomy; Situs Inversus; Case Report; India.

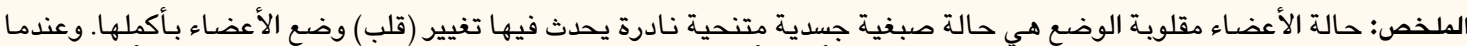

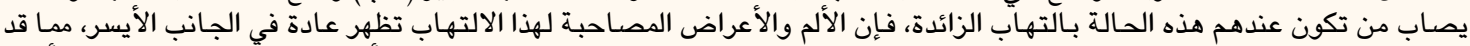

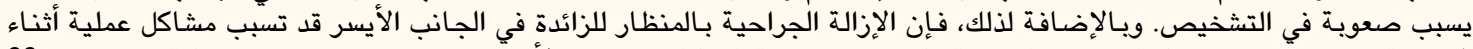

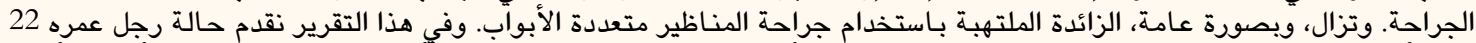

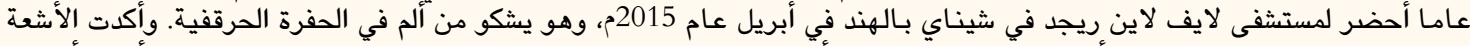

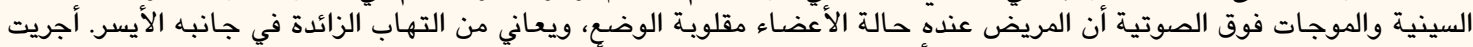

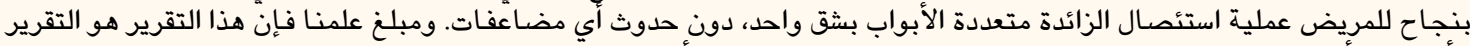

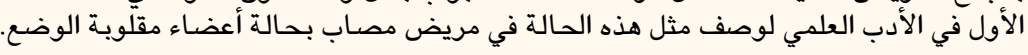
كلمات مفتاحية: جراحة المناظير؛ إزالة الزائدة؛ تغيير وضع الأعضاء؛ تقرير حالة؛ الهند.

S ITUS INVERSUS TOTALIS (SIT) IS A RARE autosomal recessive anomaly whereby the organs are located on the opposite side of the body to their normal positions; the condition was first reported by Fabricius in 1600. ${ }^{1,2}$ The incidence of SIT is estimated to vary between 1 in 5,000 and 1 in 20,000 individuals. ${ }^{1}$ When patients with this anomaly present with a surgical emergency-such as appendicitis-diagnosis can be challenging. ${ }^{3}$ Acute appendicitis requires prompt surgical intervention and the laparoscopic appendectomy is the current gold-standard surgical treatment. Even for patients with SIT, a multi-port laparoscopic appendectomy allows minimal access surgery by positioning the ports and monitor in a mirror-image fashion on the opposite side. However, one of the most popular recent advances in minimal access surgery is the single-incision multi-port surgery. ${ }^{4}$ This technique is more technically demanding due to the loss of triangulation; however, it allows for an improved postsurgical cosmetic appearance and a faster recovery time. ${ }^{4}$ This case report describes a young male patient with SIT who presented with acute appendicitis and successfully underwent a single-incision multi-port appendectomy.

\section{Case Report}

A 22-year-old male presented to the Lifeline Institute of Minimal Access Surgery, Chennai, India, in April 2015 with pain and discomfort in the left iliac fossa, which had begun around the umbilicus and moved to 

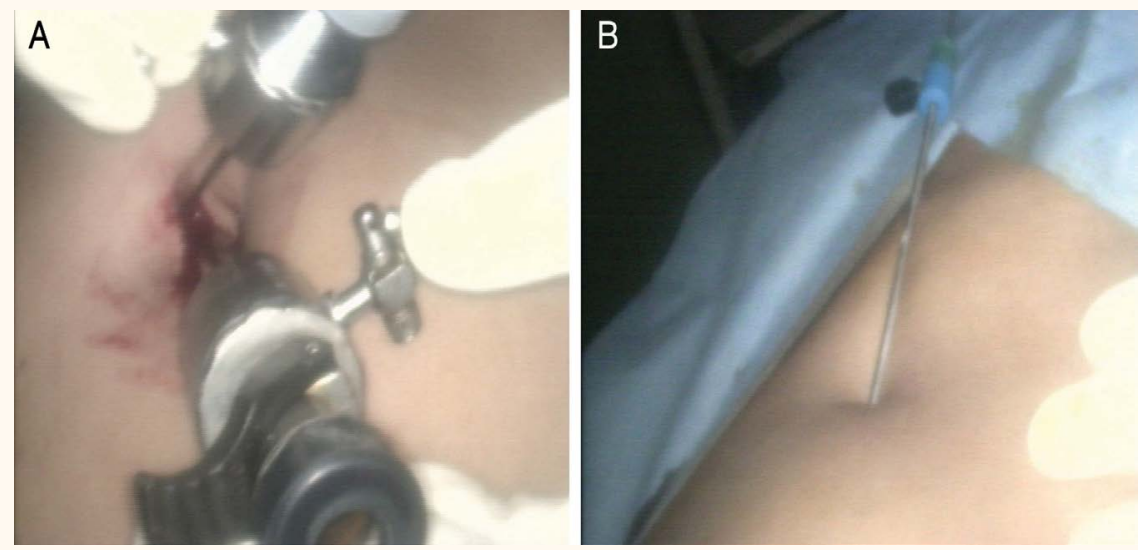

Figure 1 A\&B: Intrasurgical photographs of (A) the single-incision multi-port appendectomy performed on a patient with situs inversus totalis using (B) alligator needle/grasper forceps.

the left lower quadrant of the abdomen. There was no pain in his right side or anywhere else in the abdomen. The patient suffered from loss of appetite and vomiting. A physical examination revealed that the patient was mildly tachycardic, febrile and had severe localised tenderness in the left iliac fossa in addition to rebound tenderness and abdominal guarding. When asked for his medical history, the patient informed the physician that his heart was on the other side. A chest X-ray and ultrasound confirmed the diagnosis of SIT with an acutely inflamed appendix in the left iliac fossa. Consequently, a single-incision multi-port appendectomy was performed.

A thorough laparoscopy of the internal organs was performed using a telescope inserted through a supraumbilical incision of $10 \mathrm{~mm}$, including an examination of the terminal $90 \mathrm{~cm}$ section of the ileum in the small bowel. The inflamed appendix was observed along the left paracolic gutter. A second port was introduced by extending the incision by an additional $5 \mathrm{~mm}$ and inserting a $5 \mathrm{~mm}$ trocar directed towards the left iliac fossa, away from the lateral edge of the incision [Figure 1A]. The appendix was gently lifted up using
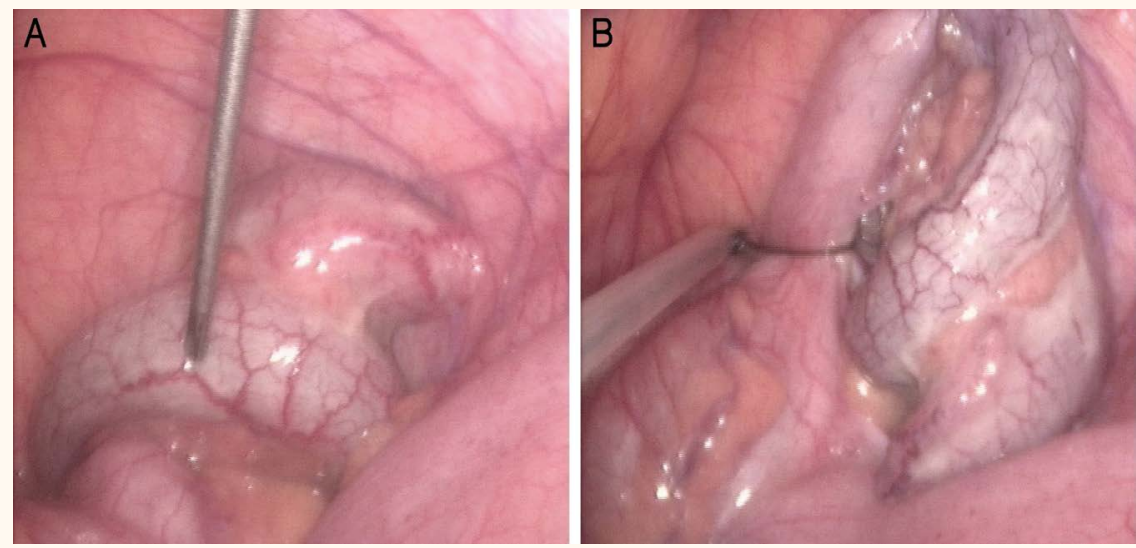

Figure 2 A\&B: Intrasurgical photographs of (A) the coiled and inflamed appendix in the left iliac fossa of a patient with situs inversus totalis and (B) the looping of the ligature around the base of the appendix. alligator needle/grasper forceps (Alligator ${ }^{\mathrm{TM}}$ Retrieval Device, Medtronic, Fridley, Minneapolis, USA) [Figure 1B]. The appendix was coiled upon itself and was carefully released [Figure 2A]. A small amount of purulent fluid was removed from the left iliac fossa by suctioning. An ultrasonic scalpel was used to dissect the complete mesoappendix, with the alligator needle/ grasper forceps elevating the shaft of the appendix. Two ENDOLOOP ${ }^{\circledR}$ ligatures (Ethicon Inc., Johnson \& Johnson, Somerville, New Jersey, USA) were looped around the appendix from the port with the support of the alligator needle/grasper forceps [Figure 2B]. For the third tie, a cobbler's suture needle was used to suture the appendix base through the needle hole of the alligator needle/grasper forceps with dissecting forceps (Laparoscopic Maryland Dissecting Forceps, Medline Industries Inc., Mundelein, Illinois, USA) in the port. The appendix was cut between the ties. The fluid was suctioned out and the appendix was removed through the incision from the lateral port with camera assistance. The patient made a smooth postoperative recovery and was healthy at a 20-day follow-up. 


\section{Discussion}

Appendectomies among SIT patients have previously been reported, with 69 cases to date in the scientific literature. ${ }^{5}$ When patients with SIT present with acute appendicitis, the diagnosis can be confusing. ${ }^{6,7}$ In cases of a straightforward and total contralateral transposition of the viscera, the appendix and caecum can easily be identified on the left side. However, in patients with malrotation of the viscera, the appendix may be in the subhepatic or subsplenic positions which can cause diagnostic problems during surgery. ${ }^{8}$ Disconcertingly, up to $15 \%$ of SIT patients with appendicitis report pain on the right side. ${ }^{3}$ A small proportion of those without neural situs inversus complain of appendicular pain on the right side as well. 5,7,9,10 This anomaly occurs due to a failure in the transposition of the nervous system, with the leftsided appendix still causing right iliac fossa pain. As a result, ultrasonography or computed tomography should be performed to confirm the diagnosis of SIT, as was done in the present case.

The commonly recommended strategy for treating patients with a left-sided appendix due to intestinal malrotation, SIT or a similar abnormality is a diagnostic laparoscopy in the periumbilical area, after which ports can be placed strategically depending upon the pathology observed and on the quadrant affected. ${ }^{11}$ Commonly placed trocar positions for laparoscopic appendectomies include umbilical and suprapubic trocars and trocars placed in the left upper quadrant. In some patients, particularly those with a slightly elevated caecum on the left side, the left upper quadrant port is replaced by an epigastric port. ${ }^{11}$ Very few surgeries for left-sided appendicitis have been carried out laparoscopically (10.2\%). ${ }^{5}$ While there are several reports of single-incision or single-port cholecystectomies in patients with SIT, the present case report appears to be the first in the medical literature of a single-incision appendectomy in a patient with SIT, although the technique has been mentioned previously. ${ }^{12-17}$

The single-incision procedure described in the current case report took only a few minutes longer than a standard multi-port appendectomy. Ultrasonic shears are not normally used for appendectomies as they increase the cost of the procedure; ${ }^{11,18}$ however, in the present case, they were deemed suitable as alligator needle/grasper forceps would not be able to coagulate the tissues if mesoappendix bleeding occurred with cautery. Moreover, use of the alligator needle/grasper forceps permitted traction of the appendix during the mesoappendix dissection as well as the looping of the ligatures around the base of the appendix through the port. Additionally, detailed examination of the terminal end of the small bowel was possible using solely the bowel-holding forceps in the port. Several reports have recommended alligator needle/grasper forceps in single-port or reducedport cholecystectomies ${ }^{11,19}$ Using the alligator forceps in one hand and the energy device (e.g. harmonic scalpels, monopolar or bipolar electrosurgical devices or electrocautery devices) in the other also reduces the potential triangulation problems that may arise during a single-port surgery. In the present case, a cobbler's needle was used to suture the appendix base through the needle hold of the alligator needle/grasper forceps with dissecting forceps in the port. This type of intracorporeal suturing is usually deployed in single-port fundoplication surgeries and single-port sleeve gastrectomies. ${ }^{4}$ Despite concerns regarding triangulation, the authors would recommend the combination of alligator needle/grasper forceps and a 10 and $5 \mathrm{~mm}$ port through the same incision.

Although two ports were used in the current case, both ports were implanted through a single $15 \mathrm{~mm}$ incision; the most accurate term for this procedure is therefore a single-incision double-port appendectomy. The alligator needle/grasper forceps and the cobbler's needle were both passed through a single needle hole of $1.5 \mathrm{~mm}$ in diameter, justifying the use of the aforementioned term. Although a singleport device might have facilitated the handling and removal of the appendix, it is departmental policy at the Lifeline Institute of Minimal Access Surgery to perform single-incision multi-port surgeries so as to decrease patient costs.

\section{Conclusion}

A single-incision appendectomy is a viable alternative to multi-port appendectomies in patients with SIT. To the best of the authors' knowledge, this is the first case to be reported in the English medical literature.

\section{References}

1. Phothong N, Akaraviputh T, Chinswangwatanakul V, Trakarnsanga A. Simplified technique of laparoscopic cholecystectomy in a patient with situs inversus: A case report and review of techniques. BMC Surg 2015; 15:23. doi: 10.1186/ s12893-015-0012-6.

2. Dalal JS, Kalsey G, Rai H, Chanana A, Mittal S, Dalal V, et al. Situs inversus totalis. J Punjab Acad Forensic Med Toxicol 2004; 1:35-6.

3. Oh JS, Kim KW, Cho HJ. Left-sided appendicitis in a patient with situs inversus totalis. J Korean Surg Soc 2012; 83:175-8. doi: $10.4174 /$ jkss.2012.83.3.175. 
4. Canes D, Desai MM, Aron M, Haber GP, Goel RK, Stein RJ, et al. Transumbilical single-port surgery: Evolution and current status. Eur Urol 2008; 54:1020-9. doi: 10.1016/j. eururo.2008.07.009.

5. Naik MB, Roa KS. Laparoscopic appendicectomy in situs inversus totalis. J Evol Med Dent Sci 2015; 4:5064-7. doi: $10.14260 /$ jemds/2015/738

6. Golash V. Laparoscopic management of acute appendicitis in situs inversus. J Minim Access Surg 2006; 2:220-1. doi: $10.4103 / 0972-9941.28184$

7. Akbulut S, Caliskan A, Ekin A, Yagmur Y. Left-sided acute appendicitis with situs inversus totalis: Review of 63 published cases and report of two cases. J Gastrointest Surg 2010; 14:1422-8. doi: 10.1007/s11605-010-1210-2.

8. Palanivelu C, Rangarajan M, John SJ, Senthilkumar R, Madhankumar MV. Laparoscopic appendectomy for appendicitis in uncommon situations: The advantages of a tailored approach. Singapore Med J 2007; 48:737-40.

9. Machado NO, Chopra P. Laparoscopic cholecystectomy in a patient with situs inversus totalis: Feasibility and technical difficulties. JSLS 2006; 10:386-91.

10. FranklinMEJr,AlmeidaJA,PérezER,MichaelsonRL,MajarrezA Cholecystectomy and appendectomy by laparoscopy in a patient with situs inversus totalis: A case report and review of the literature. Assoc Mex Surg Endoscóp 2001; 2:150-3.

11. Kollmar O, Z'graggen $\mathrm{K}$, Schilling MK, Buchholz BM, Büchler MW. The suprapubic approach for laparoscopic appendectomy. Surg Endosc 2002; 16:504-8. doi: 10.1007/ s00464-001-9027-4

12. Han HJ, Choi SB, Kim CY, Kim WB, Song TJ, Choi SY. Singleincision multiport laparoscopic cholecystectomy for a patient with situs inversus totalis: Report of a case. Surg Today 2011; 41:877-80. doi: 10.1007/s00595-010-4387-9.
13. de Campos Martins MV, Pantaleão Falcão JL, Skinovsky J, de Faria GM. Single-port cholecystectomy in a patient with situs inversus totalis presenting with cholelithiasis: A case report. J Med Case Rep 2012; 6:96. doi: 10.1186/1752-1947-6-96.

14. Uludag M, Yetkin G, Kartal A. Single-incision laparoscopic cholecystectomy in situs inversus totalis. JSLS 2011; 15:239-43. doi: 10.4293/108680811X13071180407032.

15. Bozkurt S, Coskun H, Atak T, Kadioglu H. Single incision laparoscopic cholecystectomy in situs inversus totalis. J Surg Tech Case Rep 2012; 4:129-31. doi: 10.4103/2006-8808.110264.

16. Khiangte E, Newme I, Patowary K, Phukan P. Single-port laparoscopic cholecystectomy in situs inversus totalis using E.K. glove port. J Minim Access Surg 2013; 9:180-2. doi: 10.41 03/0972-9941.118838.

17. Zachariah SK. Feasibility of single-incision laparoscopic surgery for appendicitis in abnormal anatomical locations: A single surgeon's initial experience. J Minim Access Surg 2013; 9:13-18. doi: 10.4103/0972-9941.107128.

18. Ignacio RC, Burke R, Spencer D, Bissell C, Dorsainvil C, Lucha PA. Laparoscopic versus open appendectomy: What is the real difference? Results of a prospective randomized double-blinded trial. Surg Endosc 2004; 18:334-7. doi: 10.1007/ s00464-003-8927-x.

19. Blanco FC, Kane TD. Single-port laparoscopic surgery in children: Concept and controversies of the new technique. Minim Invasive Surg 2012; 2012:232347. doi: 10.1155/ 2012/232347. 